\title{
Synthesis and optical characterization of zinc borotellurite glass doped with lanthanum nanoparticles
}

\begin{abstract}
A glass series with chemical composition of $\{[(\mathrm{TeO} 2) 0.7(\mathrm{~B} 2 \mathrm{O} 3) 0.3] 0.7(\mathrm{ZnO}) 0.3\} 1-\mathrm{x}$ ( $\mathrm{La}$ NPs) $\mathrm{x}$ where $\mathrm{x}=0.01,0.02,0.03,0.04$ and 0.05 molar fraction was synthesized through conventional melt-quenching method. The fabricated glasses were characterized by using UV-Vis and FTIR technique in the range of 220 to $800 \mathrm{~nm}$ and 280 to $2000 \mathrm{~cm}-1$ respectively. Various absorption bands that were recorded in FTIR spectra indicates the presence of $\mathrm{TeO} 4, \mathrm{BO} 3$ and $\mathrm{BO} 4$ unit. In this research, indirect energy band gap showed an increasing trend while refractive index values decreases as amount of La NPs increases due to the decrement of high polarizability nonbridging oxygen number in the glass system. Other optical parameter that also take part in governing the value of refractive index such as electronic polarizability was also determined.
\end{abstract}

Keyword: Borotellurite glass; Electronic polarizability; Indirect energy band gap; Nanomaterial; Refractive index 